\title{
OCTAVIO PAZ Y ESPAÑA
}

\author{
POR \\ PETER G. EARLE \\ University of Pennsylvania
}

«El camino se hace al andar», había afirmado Antonio Machado, mucho antes de que Octavio Paz emprendiera su camino de Galta ( $E l$ mono gramático, 1970), alucinante peregrinación a través del lenguaje: extraño viaje místico-erótico por un borroso paisaje de la India. Fue uno de "Les Sentiers de la Création», bajo cuyo título general se publicó $L e$ Singe grammarien en París, en 1972 ${ }^{1}$. Para Paz, discípulo temprano de Machado en otro sentido, especialmente en su común perspectiva sobre la persistente «otredad» de cada persona, el camino de la poesía no se hace. Más bien se deshace a cada paso, para reconstituirse siempre en otro camino. Así nos dice, al menos, en su testimonio:

Al comenzar estas páginas decidí seguir literalmente la metáfora del título de la colección a que están destinadas, Los Caminos de la Creación, y escribir, trazar un texto que fuese efectivamente un camino y que pudiese ser leído, recorrido como tal. A medida que escribía, el camino de Galta se borraba o yo me desviaba y perdía en sus vericuetos. Una y otra vez tenía que volver al punto de comienzo. En lugar de avanzar, el texto giraba sobre sí mismo. ¿La destrucción es creación? No lo sé, pero sé que la creación no es destrucción. A cada vuelta el texto se desdoblaba en otro, a un tiempo su traducción y su transposición: una espiral de repeticiones y de reiteraciones que se han resuelto en una negación de la escritura como camino ${ }^{2}$.

Podría parecer, a primera vista, que Paz se nos presenta como teórico estructuralista de última - de por entonces (1970)— moda. Pero en rea-

1 El texto original, en español, no se publicó hasta 1974.

2 «E1 mono gramático», en Poemas (1935-1975) (Barcelona: Seix-Barral, 1979), pp. $580-581$. 
lidad se trata de una convicción crítica en la que el poeta siempre se ha mantenido firme: la lengua, y no la nacionalidad, es el fundamento continuo de una literatura. Una sociedad y una cultura históricas perduran por el vigor de su verdadera base: su idioma, del que nacen, a su vez, innumerable lenguajes. Una literatura adquiere forma y vigencia al adquirir conciencia crítica. Esa conciencia engendra una nueva sensibilidad, nuevas perspectivas, nuevos valores: Rubén Darío en su momento; Borges en el suyo; después, Octavio Paz, etc.

En el prólogo a los ensayos de Puertas al campo (1966), Paz recuerda a sus lectores que hacía apenas cuarenta años (i.e., por los años veinte) los mexicanos veían el mundo a través de una Europa representada principalmente por Francia, y añade: «nunca me ha parecido delito ser afrancesado». Más adelante se refiere al «gran fragmento de nuestro ser que se llama España» y a «la imposibilidad del diálogo» con los españoles, aunque «nuestra relación ha oscilado siempre entre una adhesión sin reservas y una indiferencia no menos absoluta» ${ }^{3}$.

Hubo tres memorables momentos de la historia española (la ocupación napoleónica de 1808, la guerra con los Estados Unidos en 1898, la guerra civil de 1936 a 1939) en los que «una adhesión sin reservas» efectivamente se realizó. Sobre todo durante y después de la guerra civil. «E1 19 de julio de 1936 -declara Paz en un discurso de 1951 en París- el pueblo español apareció en la historia como una milagrosa explosión de salud ${ }^{4}$. A continuación veremos algunas reverberaciones de esa explosión en la obra del poeta mexicano.

Los poetas más importantes de Hispanoamérica (entre los nacidos antes de 1915) comparten una circunstancia biográfica fundamental: su experiencia vital en España. Primero, Rubén Darío. Después, Alfonso Reyes, César Vallejo, Vicente Huidobro, Pablo Neruda, Octavio Paz. Cada uno de ellos cimentó relaciones que trascendían la pura intelectualidad. Hasta el propio Jorge Luis Borges, eminente desconocedor de las letras españolas (y de gran parte de las hispanoamericanas) posteriores a Quevedo y Gracián, pasó la primera etapa de su juventud ultraísta en la Madre Patria, estimulado por la conversación de Rafael CansinosAssens.

Entre esos poetas, probablemente Paz ha constituido el puente intelectual más firme entre España y las Américas de habla española. El en-

3 «Nota», Puertas al campo, 2." ed. (México: Universidad Nacional Autónoma de México, 1967), pp.6-7.

4 "Aniversatio español», 19 de julio de 1951, en El ogro filantrópico (Barcelona: Seix-Barral, 1979), p. 203. 
tró en su mayoría de edad literaria al presenciar, en 1937, el gran acontecimiento revolucionario, fratricida y civil de España ${ }^{5}$.

Pero hubo un importante presentimiento, casi se podría decir previsión, de esa contienda en la amistad que formó Paz con un compañero de escuela en la ciudad de México en 1929. El compañero se llamaba José Bosch; era catalán y participaba activamente en las protestas y huelgas estudiantiles, y en la campaña presidencial de José Vasconcelos, de México. Por esas mismas actividades fue detenido y deportado, desde el puerto de Veracruz, al año siguiente. Pasaron los años y no se sabía de él hasta que, a principios de la Guerra Civil, apareció su nombre en una lista de caídos en el frente de Aragón que se publicó en un diario de México. Con ese motivo, Paz escribe, en 1937, su «Elegía a un compañero muerto en el frente de Aragón» («Has muerto, camarada, / en el ardiente amanecer del mundo...»). Algunos meses después, en 1937 o a principios de 1938, Paz se encontraba en Barcelona, en una reunión de la Sociedad de Amigos de México. Al joven mexicano le tocaba leer la Elegía y dos o tres poemas más; al empezar su recital, con la debida sensibilidad fúnebre, se fijó en la innegable presencia, en primera fila, de José Bosch. Esto y mucho más lo cuenta Paz en una extensa nota a su Elegía ${ }^{6}$, mucho más interesante, por cierto, que el poema. Ya en 1929, el adolescente Bosch había introducido al adolescente Paz a la lectura del anarquista Kropotkin, de Ferrer, de Proudhon y otros. Al día siguiente del recital de Barcelona, Paz habló por última vez con Bosch, y después no supo más de él.

Me he referido a esta amistad porque su desarrollo anticipa, de cierta manera, la trayectoria literaria de Octavio Paz, y a su pensamiento histórico. «El ardiente amanecer del mundo», que para tantos - dentro y fuera de España - representaba la Guerra Civil, pronto se transformaría en tuna sangrienta pesadilla. La solidaridad inicial se deshizo en luchas internas (entre liberales, anarquistas, comunistas). Frente al monolito fascista, la unidad se volvió dispersión. Para 1939 España era un cementerio de esperanzas. En agosto de 1945 dos bombas atómicas estallaron

5 Parece que hay una confusión de fechas o, tal vez, sólo una errata. Según Alfredo Roggiano («Persona y ámbito de Octavio Paz», en Roggiano (ed.), Octavio Paz [Madrid: Editorial Fundamentos, 1979], pp. 10-11) y Pablo Neruda (Confieso que he vivido: Memorias [Caracas: Seix-Barral, 1974], p. 182), Paz estuvo en España, y también en Francia, en 1937. Según Paz, en su extensa nota sobre «Elegía a un compañero muerto en el frente de Aragón» (Poemas [1935-1975], pp. 666-673), escribió la elegía a su amigo en 1937 y «en 1938 estuve en España: Barcelona, Valencia, el frente del Sur, donde mandaba una brigada un pintoresco mexicano: Juan B. Gómez» (ibid., p. 671).

6 Ibid., pp. 666-673. 
sobre dos ciudades japonesas, mutilando permanentemente el porvenir. En el Epílogo de la primera edición de El arco y la lira (1956) Paz observa:

La conciencia de la historia se ha revelado al fin como conciencia trágica; el ahora no se proyecta ya en un futuro: es un siempre y un aquí. El hombre está inmerso en algo último y definitivo, que afecta totalmente a su presente, su pasado y su futuro. He aquí que el poeta descubre lo trágico, y con él su pueblo y su mundo.

El tono es innegablemente unamuniano; la historia confirma una desesperación compartida, un quiero-y-no-puedo enunciado por poetas y profetas y experimentado por todos: sentimiento trágico. En el Epílogo de la segunda edición («Los signos en rotación», 1967) aumenta la incertidumbre; ahora «la historia no tiene sentido», pues «nuestro tiempo es el fin de la historia como futuro imaginable o previsible».

A partir de la Segunda Guerra Mundial, en efecto, «el ahora no se proyecta ya en un futuro». La guerra de España y la guerra mundial tenían más de epílogo que de prólogo, tanto para los historiadores como para los poetas. Sobre todo para Octavio Paz, escritor profundo por su clarividencia poética y su conciencia histórica. En aquel ambiente de fin de época («el del fin de la historia como futuro imaginable o previsible»), que hemos vivido desde 1945, hay que situar sus poemas y ensayos.

Ahora me permito una confesión crítica de gustibus. Estimo de Unamuno en varios aspectos --especialmente el dramático: su encarnación de la lucha por la fe- su sentimiento trágico. Por otra parte, soy orteguiano; más que las obras me interesa el creador en su circunstancia: Cervantes, Whitman, Thomas Mann y García Márquez en el torbellino de sus respectivos mundos; ellos me dejan ver cómo les afecta el tiempo - mejor dicho, dos tiempos- en que viven (cada uno de ellos vive simultáneamente en varios tiempos). Para el lector circunstancial no hay abstracciones ni textos autónomos ni auto-reflexiones que valgan en sí. Todo sujeto y todo objeto son interdependientes; la razón es vital; la emoción crea realidades; la realidad, emociones. Esto lo he aprendido (o extraído) de Ortega y de Unamuno juntos. Ortega me desilusiona cuando, a partir de 1936, él mismo pierde de vista su circunstancia y opta por el silencio frente al totalitarismo (ya crecido), que había previsto con tanta clarividencia en 1929 ( $L$ a rebelión de las masas). Pero me imagino que no fue tanto el caso de una entrega de principios como una pérdida de yisión. Parecía que el maestro ya no estaba, para emplear su propia frase, «a la altura de los tiempos», como si los ojos miraran sin la ayuda del resto de su ser. 
No se tome este paréntesis como una condena literaria, sin embargo; en México se leía a Ortega con afán y provecho; él había estimulado al lector hispanoamericano, especialmente al mexicano, a aumentar su conciencia histórica, y en el fondo compartía con Unamuno su sentimiento trágico. Octavio Paz resume el caso así:

La pérdida de la imagen del futuro, decía Ortega y Gasset, implica una mutilación del pasado. Así es: todo lo que nos parecía cargado de sentido se ofrece ahora ante nuestros ojos como una serie de esfuerzos y creaciones que son un no-sentido. La pérdida de significacado afecta a las dos mitades de la esfera, a la muerte y a la vida: la muerte tiene el sentido que le da nuestro vivir; y éste tiene como significado último ser vida ante la muerte. Nada nos puede decir la técnica sobre todo esto. Su virtud filosófica consiste, por decirlo así, en su ausencia de filosofía. («Los signos en rotación» en El arco y la lira, 2. ${ }^{a}$ ed., 1967.)

Fundamentalmente, el sentimiento trágico de Unamuno, transformado en la obra de Paz en conciencia trágica, anticipaba esta progresiva "pérdida de significado». Los conceptos de vida y muerte -es decir, de vida frente a la muerte y de muerte frente a la vida- ceden el paso a la técnica, a la no-filosofía, a la nueva selva de conocimientos denominada por los peritos en materia de máquinas computadoras como «informática». Para Paz, la técnica se interpone entre los individuos y el mundo; además, «no es una visión porque no concibe al mundo como figura, sino como algo más o menos maleable para la voluntad humana». El «espacio homogéneo» que ahora es el mundo se debe a una continua expansión en nuestras vidas de la técnica (de modo que el cómo hacer las cosas va desplazando los motivos del por qué hacerlas), y también a la «aceleración del suceder histórico» en nuestro siglo. Parece que la poesía de Paz mismo ha reflejado el movimiento hacia «el espacio homogéneo» creado por la técnica. Compárense Piedra de sol, experiencia alternativamente tierna y violenta frente a la historia (mexicana, española y universal), y el poema posterior, Blanco. En Blanco la historia queda abandonada, y la finalidad temática se concentra en el intento de esclarecer la realidad del poema en sí, realidad múltiple e intercambiable que puede leerse en diversos órdenes y combinaciones. En sentido estricto, Blanco no es una creación, sino el alucinante espectáculo de una creación en el proceso de hacerse, en el que alusiones fugaces a la vida orgánica («la palabra en la punta de la lengua», «la tierra es un lenguaje calcinado», "verdea la palabra», «estás desnuda / como una sílaba», etc.) sirven para reflejar un texto. Como bien ha visto Pere Gimferrer, «los elementos de la realidad exterior al poema que aparecen en él... no se encaminan a 
situarlo en el espacio o en el tiempo externos a la escritura, sino que, por el contrario, tienen por misión reforzar los datos textuales como tales, de suerte que su función es exactamente inversa a la que suelen desempeñar la metáfora, la metonimia y aun el correlativo objetivo» ${ }^{7}$. Así, las cosas y los seres son señas y símbolos del lenguaje y no al revés. A primera vista, esta desmaterialización creadora es simple sumisión a la técnica; ya que no sabemos el por qué, entretengámonos con el cómo; los medios constituirán el mensaje. Así, Paz mismo parece cumplir con la profecía de «Los signos en rotación» en sus poemas más recientes. En efecto, habitamos «un espacio homogéneo». Los temas básicos son el silencio, el vacío, la dispersión, el olvido. ¿La página en blanco se convertirá en un sumidero de la historia, los amores y la naturaleza?

En verdad, no. Es cierto que en gran parte de su poesía han desaparecido las referencias históricas; en cambio, la vitalidad interior de los instantes va en aumento. La intensidad de la experiencia es de una belleza constitutiva porque enaltece el deseo:

\section{Espiral de los ecos, el poema es aire que se esculpe y se disipa, fugaz alegoría de los nombres verdaderos.}

Es lo que escribe hacia el fin de Pasado en claro (1974), extenso poema de evocaciones en donde los murmullos de su propio pasado van entretejidos con las alusiones a su experiencia creadora.

Obvio es que Paz goza del oxímoron: «el presente es perpetuo»; «la quietud en movimiento»; «ruinas vivas en un mundo de muertos en vida», etc. $Y$ es posible que su inclinación a pensar a través de los contrarios le haya incitado a alejarse cada vez más de la historia, a favorecer 1a Palabra a expensas de la Realidad, a soslayar un poco el mundo hispanomexicano de su origen al fascinarse por la cultura meditativa de Oriente. En general, su perspectiva se ha movido desde un concepto de unidad, o de los hombres modernos unidos en su misma soledad (El laberinto de la soledad, que sigue siendo el ensayo clásico de Paz; Piedra de sol, que sigue siendo su poema clásico), a otro concepto de dispersión (Blanco; «Poema circulatorio», subtítulo: «Para la desorientación general»; El mono gramático). En varios ensayos de crítica literaria Paz señala la misma trayectoria dentro del idioma: la lengua castellana, que al extenderse a las Américas fue diversificándose, particularmente en

7 Pere Gimferrer, Lecturas de Octavio Paz (Barcelona: Editorial Anagrama, 1980), pp. 61-62. 
literatura. En el pasaje siguiente de una conferencia de 1976 ("Alrededores de la literatura hispanoamericana») nótese el pensamiento neoorteguiano, esto es, lo crucial de cada perspectiva:

Una obra literaria es el producto de distintas circunstancias combinadas de manera imprevisible: el carácter del escritor, su biografía, sus lecturas, el medio en que le ha tocado vivir y otros accidentes. Circunstancias parecidas en temperamentos diferentes producen obras antagónicas, o, al menos, disímiles. Además, la religión, la filosofía o los conceptos que cada uno tiene sobre este mundo y el otro. Entre Jorge Guillén y José Gorostiza hay indudables afinidades de sensibilidad y también comunidad de lecturas (Valéry), pero estas semejanzas se bifurcan y resuelven en dos visiones opuestas: al español lo alza la ola del ser y al mexicano la misma ola lo sepulta. La misma transparencia verbal dibuja, con nitidez semejante, los dos monosílabos contraídos: Sí y No.

Poeta-pensador que no ha olvidado sus lecturas juveniles de historia (entre ellas los Episodios nacionales, de Pérez Galdós), Octavio Paz se ha ido definiendo a través de sus poesías y ensayos. Es decir, se ha definido culturalmente a base de su contacto con otras culturas; en orden cronológico, la española, la norteamericana, la francesa, la india o hindú. A1 principio de estas notas señalé la fundamental importancia de la gurerra civil en España para la perspectiva histórica de Paz. Lo mejor de España refloreció, desde esa guerra, en el Nuevo Mundo, y notablemente en México. El presidente mexicano de entonces, Lázaro Cárdenas, y con muy contadas excepciones ${ }^{8}$ la intelectualidad mexicana entera - tanto los escritores, artistas y periodistas como los centros docentes-, encontraron en la lucha española grandes estímulos culturales. Para Paz hay un importante paralelo entre la historia española y la hispanoamericana desde las guerras de independencia; consiste en las revueltas y revoluciones que —en la Península y también en Hispanoamérica- «han sido tentativas por romper con un pasado que nos ahoga y una búsqueda de nuevas formas políticas y sociales» ${ }^{9}$.

«Una adhesión sin reservas» de México a la España democrática y, después, a la peregrina efectivamente se realizó. Por parte de España también se realizó - observa Paz- un histórico reconocimiento de

8 La más destacada de ellas: José Vasconcelos, fundador y editorialista de una efímera revista fascista, El Timón (1940-1941), de México. Véase, al respecto, el estudio de Itzhak-Bar Lewaw M., La revista «Timón» y José Vasconcelos (México: 1970).

9 «México y los poetas del exilio español», en Hombres en su siglo y otros ensayos (Barcelona: Seix-Barral, 1984), p. 50. 
América. «Los españoles vislumbraron, tras un prolongado olvido, su otra dimensión histórica, no la etropea, sino la americana». ${ }^{10}$ La relación España-América abarca - escribe- tres etapas: conocimiento (el descubrimiento y la conquista), desconocimiento (cuando, hacia fines del siglo xvirl, los hispanoamericanos «dejaron de reconocerse en España» y comenzaron a interesarse por la cultura francesa y la política norteamericana; fue para ellos el descubrimiento de «la modernidad») y reconocimiento (la Guerra Civil española, con sus múltiples antecedentes y repercusiones, incluso ciertas afinidades con la Revolución Mexicana). La mayor parte de este ensayo («México y los poetas del exilio español») está dedicada a la experiencia de los poetas españoles que llegaron a México desde 1939 y que poco a poco se fueron mexicanizando (Enrique Díez Canedo, Emilio Prados, Juan Gil-Albert, León Felipe, José Moreno Villa, Luis Cernuda, Manuel Altolaguirre y otros). De su llegada a Veracruz apuntó Gil-Albert estas impresiones:

La costa es allá, más que en ningún otro lugar, engañosa, aparente, atractiva: labios. México está atrás, hacia dentro y hacia lo alto; internarse por esa infinitud que nos espera tiene sus riesgos; es, nos atrevemos a expresarnos asi, fatal... La experiencia mexicana es de orden trascendente. La infinitud aguarda allí a quien se asoma a su alta planicie; la infinitud y la vez la sensación angustiosa del límite, de que allí acaba la tierra del hombre y de que toda esa luminosidad helada, plateada, de altura, que resplandece en las cosas, es ya el abismo, el más allá inhumano o sobrehumano... Se siente que la tierra se ha cerrado en redondo, que aquello es el verdadero finis terrae y que, como desde un balcón infinito, contemplamos el paso de las nubes maravillosas por las rutas inaccesibles ${ }^{11}$.

Para Octavio Paz, el reconocimiento (americano-español y españolamericano) empezó en sentido dinámico en 1937: año en que dejó el hogar, la universidad y la ciudad natal, año en que se casa con Elena Garro y se va a España, donde - podríamos decir- recomienza su educación, fue su verdadero rite of passage intelectual. «España me enseñó el significado de la palabra fraternidad», dijo a Rita Guibert (Siete voces, México: 1974).

Uno se imagina que aquella experiencia y el espíritu de fraternidad que resultó de ella también animaron sus lecturas de Cervantes, Antonio Machado, Unamuno, Ortega y Gasset, Pérez Galdós, Jorge Guillén. Cer-

\footnotetext{
10 Ibid., p. 51.

11 Juan Gil-Aibert, Los días están contados (1974), citado por Paz, Hombres: en su siglo, pp. 53-54.
} 
vantes lo ayudó a formular su teoría de analogía e ironía desarrollada en Los hijos del limo, pues el primer escritor irónico moderno fue Cervantes: Cervantes vio la contradicción entre el mundo y el trasmundo que Dante, en su Poema, había considerado como armonía. Machado le enseñó «la esencial heterogeneidad del ser» o «la incurable otredad que padece lo uno», especialmente entre mexicanos y poetas. Unamuno le demostró la importancia de la «intrahistoria»: de ser historia al mismo tiempo que estar en la historia, y del sentimiento trágico en los individuos y los pueblos. Y Ortega y Gasset - quien desconocía casi sistemáticamente la importancia de la América Latina ${ }^{12}$ - le ayudó a definir la circunstancia histórica de los mexicanos y otros pueblos americanos. Pérez Galdós, cuyos Episodios nacionales de la segunda serie leyó Paz de muy joven en la biblioteca de su abuelo, lo introdujo al tema de las dos Españas a través de los personajes Salvador Monsalud (liberal ejemplar) y Carlos Garrote (militante carlista) su medio-hermano, y los caracterizó como seres complementarios en sus respectivos fanatismos. Jorge Guillén, al exaltar en sus instantes de revelación

(Todo está concentrado

Por siglos de raíz

Dentro de este minuto,

Eterno para mí),

le dio ejemplos de la plenitud del ser reservada para los mejores poetas y los mejores poemas, y la lección de que éstos (v. gr., «Más allá», del propio Guillén) son semillas de otros poemas.

$12 \mathrm{Paz}$ afirma que Ortega y Gasset, tras «sus expediciones por tierras desconocidas... no colonizaba: descubría». ("José Ortega y Gasset: el cómo y el para qué», en Hombres en su siglo, p. 98). Si Paz dice esto en sentido figurado, refiriéndose a las lecturas del ensayista español, tiene razón. En cambio, si se refiere a las expediciones concretas de Ortega a Argentina (1916, 1928 y 1939-1942), me parece que se equivoca. Allí descubrió muy poco y expresó de varios modos su voluntad de colonizar (intelectualmente). Sobre esto véase mi trabajo, de próxima aparición, «Ortega y Gasset in Argentina: The Exasperating Colony». 
